\title{
Adenovirally delivered IFN- $\beta$ exerts antitumor effects through transient T-lymphocyte depletion and Ag-specific T-cell proliferation
}

\author{
SANG-SEOK OH ${ }^{1}$, CHAERIN MOON $^{1}$, DONG-HYEOK KIM ${ }^{1}$, HYUNKEUN SONG ${ }^{2}$, \\ SAEGWANG PARK ${ }^{3}$, YANGXIN FU ${ }^{4}$ and KWANG DONG KIM ${ }^{1}$ \\ ${ }^{1}$ Division of Applied Life Science (BK21), PMBBRC, Gyeongsang National University, Jinju; \\ Departments of ${ }^{2}$ Anatomy and Tumor Immunology, ${ }^{3}$ Microbiology, Inje University College of Medicine, \\ Busan, Republic of Korea; ${ }^{4}$ Department of Pathology, University of Chicago, Chicago, IL, USA
}

Received December 29, 2011; Accepted February 17, 2012

DOI: $10.3892 / \mathrm{ijmm} .2012 .936$

\begin{abstract}
Type I interferons (IFNs), including IFN- $\beta$, are known to enhance antigen $(\mathrm{Ag})$ presentation and to promote the expansion, survival and effector function of $\mathrm{CD}^{+}$cytotoxic lymphocytes (CTL) during viral infections. Furthermore, IFN- $\beta$ is a potent candidate for antitumor drugs; however, recombinant IFN- $\beta$ is too unstable for use in tumor therapy in vivo. In this study, we therefore examined the efficacy and mechanism of exogenous IFN- $\beta$ as a biomolecule for tumor therapy, using adenovirus encoding IFN- $\beta$ (Ad-IFN $\beta$ ) as a therapeutic agent in a mouse model. $\mathrm{Ag} 104 \mathrm{~L}^{\mathrm{d}}$ and $4 \mathrm{~T} 1$ tumor cells exposed to Ad-IFN $\beta$ showed growth retardation and cell death in vitro, and tumor growth as well as tumor metastasis was inhibited in vivo. The Ad-IFN $\beta$-mediated antitumor effect was dependent on $\mathrm{CD}^{+} \mathrm{T}$ cells in vivo, rather than on a direct cytotoxic effect of Ad-IFN $\beta$. Transient T lymphocyte depletion was observed in tumor tissue after intratumoral injection with Ad-IFN $\beta$. Despite the T lymphocyte depletion, the proliferation of $\mathrm{Ag}$-specific $\mathrm{CD}^{+} \mathrm{T}$ cells was increased in Ad-IFN $\beta$-treated mice compared to control virus-treated mice. These results suggest that IFN- $\beta$ might contribute to the inhibition of tumor growth by depleting Ag-nonspecific $\mathrm{T}$ lymphocytes and enhancing proliferation of Ag-specific $\mathrm{CD} 8^{+} \mathrm{T}$ cells.
\end{abstract}

\section{Introduction}

While therapeutic vaccination against tumors is an important approach to cancer therapy, the efficacy of such vaccination in some human tumor trials against certain tumors has been

Correspondence to: Professor Kwang Dong Kim, Division of Applied Life Science (BK21), PMBBRC, Gyeongsang National University, Jinju 660-701, Republic of Korea

E-mail: kdkim88@gnu.ac.kr

Key words: adenovirus encoding IFN- $\beta$, antigen-specific CD8 ${ }^{+}$ $\mathrm{T}$ cell, transient $\mathrm{T}$ lymphocyte depletion, tumor therapy disappointing $(1,2)$. Type I interferon (IFN) is a candidate for overcoming some obstacles in tumor therapy. Type I IFN is commonly expressed in many cell types in response to TLR (Toll-like receptor) triggering, and is most abundantly produced by plasmacytoid dendritic cells (pDCs) in response to viral and other infections (3-8). Type I IFN acts as a bridge between the innate and adaptive immune systems, as it promotes the activation, expansion, survival, and memory differentiation of $\mathrm{T}$ lymphocytes through a variety of mechanisms, including enhanced antigen (Ag) presentation, co-stimulation and crosspriming (9-15).

IFN- $\beta$ is a cytokine of type I IFN and the IFN- $\beta$ protein was first used clinically as an anticancer drug in human glioma $(16,17)$. Although the treatment showed a growthinhibitory effect on malignant glioma and melanoma, tumor regression was observed in only 10-30 and 15-20\% of the glioma or melanoma patients treated with IFN- $\beta$, respectively (16-18). The reason for the insufficient results could be the low stability of recombinant IFN- $\beta$ in vivo. Numerous animal studies have pursued IFN- $\beta$ gene therapy as a potential tumor therapy to overcome this impediment of the recombinant protein (19-23).

In this study, we investigated the immune effects of adenovirus-mediated IFN- $\beta$ (Ad-IFN $\beta$ ) gene therapy in tumor-bearing mice. Ad-IFN $\beta$ therapy induced regression of primary tumor and prevented tumor metastasis. We found that the tumor regression was dependent on $\mathrm{CD} 8^{+} \mathrm{T}$ cells, but that tumor-infiltrated lymphocytes were depleted transiently after treatment and Ag-specific T cells proliferated. This suggests that Ad-IFN $\beta$ induces tumor regression through depletion of Ag-nonspecific or regulatory $\mathrm{T}$ cells and simultaneous induction of proliferation Ag-specific $\mathrm{CD}^{+} \mathrm{T}$ cells.

\section{Materials and methods}

Mice. B6C3F1, F1 cross between C57BL/6 and C3H mice, and $\mathrm{Balb} / \mathrm{c}$ mice were purchased from Charles River. $2 \mathrm{C}$ TCR-transgenic mice with $\mathrm{Ragl}^{-/-}$-B6 background (2C mice) were used for the survey of antigen $\left(\mathrm{L}^{\mathrm{d}}\right)$-specific $\mathrm{T}$ cell proliferations. For all experiments, the mice were between the ages 
A

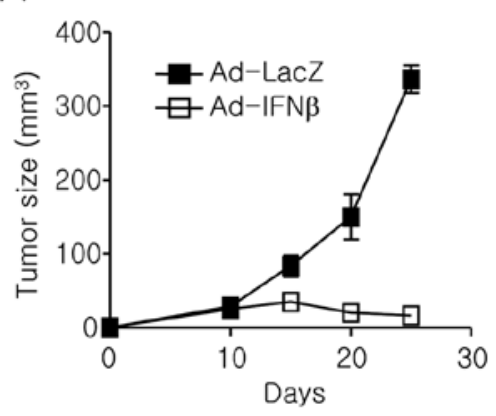

B

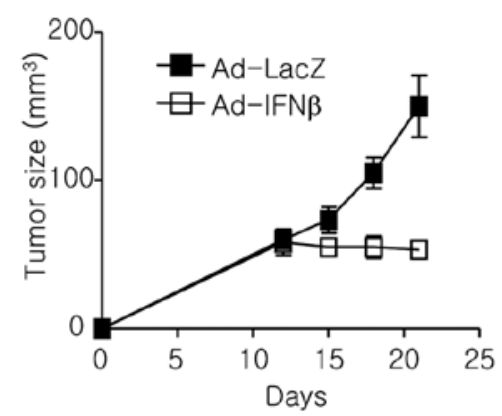

C

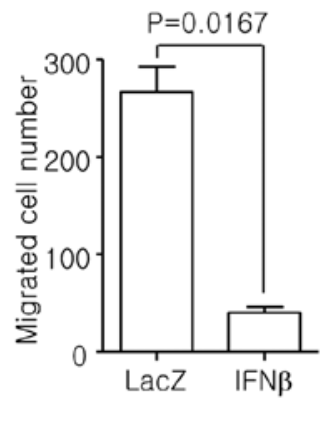

Figure 1. Antitumor effect of Ad-IFN 3 . $\mathrm{L}^{\mathrm{d}}$-overexpressing Ag104 (Ag104L ${ }^{\mathrm{d}}$ ) cells (A) or 4T1 cells (B) were injected subcutaneously into the back of B6C3F1 or Balb/c mice, respectively $(n=5)$. Ad-IFN $\beta\left(2 \times 10^{10}\right)$ was injected intratumorally on Days 9 and 11 after tumor injection. Each tumor size was calculated on the indicated days. For surgical excision of primary 4T1 tumors, mice were anesthetized and tumors were resected with sterilized instruments on Day 20 after tumor injection. Mice in which primary tumors recurred at the site of the surgical excision were eliminated from the experiments. A colonogenic assay was used to evaluate metastases by 4T1 tumors on Day 8 after the surgery (C). These experiments were repeated at least twice.

of 6-10 weeks and were used in accordance with the animal experimental guidelines set by the Animal Ethics Committee of Gyeongsang National University.

Generation of adenovirus-expressing IFN- $\beta$. To generate Ad-IFN $\beta$, we used the method described by Burnette et al (24). To construct recombinant Ad-mIFN- $\beta$, murine IFN- $\beta$ cDNA was amplified by PCR and cloned into the NotI/EcoRV sites of pAdenoVator-CMV5 $(\mathrm{CuO})$ under CMV5 promoter. pAdenoVator-mIFN- $\beta$ was linearized by $P a c$ I digestion and electroporated into electrocompetent cells BJ5183 at $2.5 \mathrm{kV}$ for recombination with the adenoviral backbone plasmid pAdenoVator $\delta E 1 / E 3$. The hybrid cosmids were selected on Kanamycin LB agar plate. PacI digestion was used to further identify recombinant cosmid containing the mIFN- $\beta$ insert. The Ad-mIFN- $\beta$ DNA was linearized by PacI digestion, and the mixture of $P a c I$ digestion without further purification was transfected into 293 cells for recombinant adenovirus production. The Ad-mIFN- $\beta$ is referred to as Ad-IFN $\beta$. Ad-LacZ was used as a control of Ad-IFN $\beta$.

Establishment of tumor and adenovirus treatments. Ag104L cells, an Ag104 fibrosarcoma cell line expressing murine $\mathrm{H}-2 \mathrm{~L}^{\mathrm{d}}$, were trypsinized, washed with media, and injected (cell number, $1 \times 10^{6}$ ) subcutaneously in the back of mice. Tumor size was determined at 3 to 4 days interval. Tumor volumes were measured along 3 orthogonal axes (a, b, and c) and calculated as tumor volume $=\mathrm{abc} / 2$. The tumor nodules were inoculated with $1 \times 10^{10}$ of adenovirus (Ad)-IFN- $\beta$ or Ad-lacZ virus intratumorally. For antibody-mediated cell depletion, $200 \mu \mathrm{g}$ per mouse anti-CD4 (GK1.5), anti-NK1.1 (PK136) or anti-CD8 (YTS.169.4.2) antibody was given to mice intraperitoneally on Days 9, 11 and 13 after primary tumor inoculation.

Evaluation of metastases by colonogenic assay. 4T1 cells $\left(5 \times 10^{4}\right)$ were inoculated subcutaneously into the area around the tail base on BALB/c mice. Ad-IFN $\beta\left(2 \times 10^{10}\right)$ was injected intratumorally on Day 9 and 11 after tumor injection. For surgical excision of primary 4T1 tumors, mice were anesthetized, and tumors were resected with sterilized instruments on Day 20 after tumor injection. Wounds were closed with metallic clips. All mice survived surgery. Mice in which primary tumors recurred at the site of the surgical excision were eliminated from the experiments. A colonogenic assay was used to evaluate metastases by 4T1 tumors on Day 8 after surgery. Lungs were collected from the mice and chopped before being dissociated in DMEM supplemented with $10 \%$ FCS containing $1.5 \mathrm{mg} / \mathrm{ml}$ collagenase type D (SigmaAldrich) (collagenase D solution) for $30 \mathrm{~min}$ in $37^{\circ} \mathrm{C}$ shaking incubator at $178 \mathrm{rpm}$ speed. Organs were then plated at various dilutions in the DMEM supplemented with $10 \%$ FCS and $60 \mu \mathrm{M}$ 6-thioguanine. Individual colonies representing micrometastases were counted after 5-10 days.

Measurement of cytokines in the tumor mass. Solid tumor tissues were weighed and homogenized, and the amount of cytokines in the supernatants was then quantified using the cytometric bead array kit (BD Biosciences, Pharmingen) on a FACSCalibur cytometer equipped with CellQuestPro and CBA software (BD Biosciences), according to the manufacturer's instruction.

Adoptive transfer of $T$ cells. A total of $2 \times 10^{6} \mathrm{~T}$ cells were labeled with carboxyfluorescein succinimidyl ester (CFSE). For reconstitution of recipients, $T$ cells were sorted using the $\mathrm{CD}^{+} \mathrm{T}$ Cell Isolation kit and the automated Magnetic Cell Sorting (Miltenyi Biotec).

Flow cytometric analysis. Single-cell suspensions of cells were isolated and incubated with anti-CD16/32 (anti-Fc $\gamma$ III/ II receptor, clone $2.4 \mathrm{G} 2$ ) for $20 \mathrm{~min}$ at room temperature and subsequently stained with conjugated antibodies. The cells were labeled with FITC-conjugated 1B2 mAb (specifically identifies $2 \mathrm{C} \mathrm{T}$ cells in $2 \mathrm{C}$ mice), FITC-conjugated antimouse anti-CD3 mAb (identifies pan-T cells) (Pharmingen, San Diego, CA), PE-conjugated anti-mouse anti-CD4 mAb (Pharmingen), and cychrome-conjugated anti-mouse anti-CD8 $\mathrm{mAb}$ (Pharmingen). Samples were analyzed on a FACSCalibur flow cytometer (BD Biosciences), and data were analyzed with FlowJo software (TreeStar, Inc.).

Statistical analysis. Data were statistically analyzed using an unpaired Student's 2-tailed t-test. Data are presented as the means, and error bars represent standard deviations (SDs). 
A

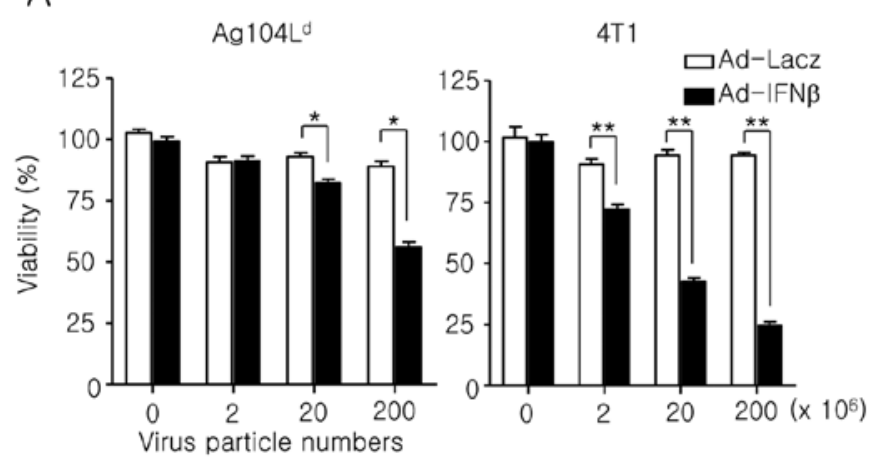

B

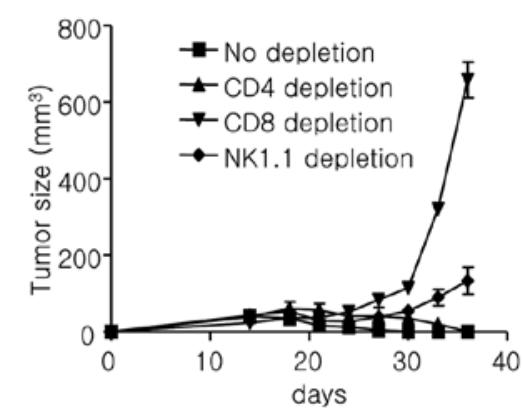

Figure 2. Ad-IFN $\beta$ induces tumor regression dependent on $\mathrm{CD} 8^{+} \mathrm{T}$ cells as well as apoptosis of tumor cells. Ag104L ${ }^{\mathrm{d}}$ or $4 \mathrm{~T} 1$ cells were cultured at a density of $5 \times 10^{4}$ cells per well in flat bottomed 96 -well plates and treated with indicated particle numbers of Ad-LacZ or Ad-IFN $\beta$ for 24 h. CellTiter $96{ }^{\circledR}$ Aq ${ }_{\text {ueous }}$ One Solution Reagent was added to each well according to the manufacturer's instructions. After $4 \mathrm{~h}$ in culture, cell viability was determined by measuring the absorbance at $490 \mathrm{~nm}$ using a 550 BioRad plate-reader (A). ${ }^{*} \mathrm{P}<0.02$ and ${ }^{* *} \mathrm{P}<0.005$. For antibody-mediated cell depletion, $200 \mu \mathrm{g}$ per mouse anti-CD4 (GK1.5), anti-NK1.1 (PK136) or anti-CD8 (YTS.169.4.2) antibody was given to mice intraperitoneally on Days 9, 11 and 13 after primary tumor inoculation. Ad-IFN $\beta$ was injected intratumorally on Days 12 and 15 after primary tumor inoculation (B).
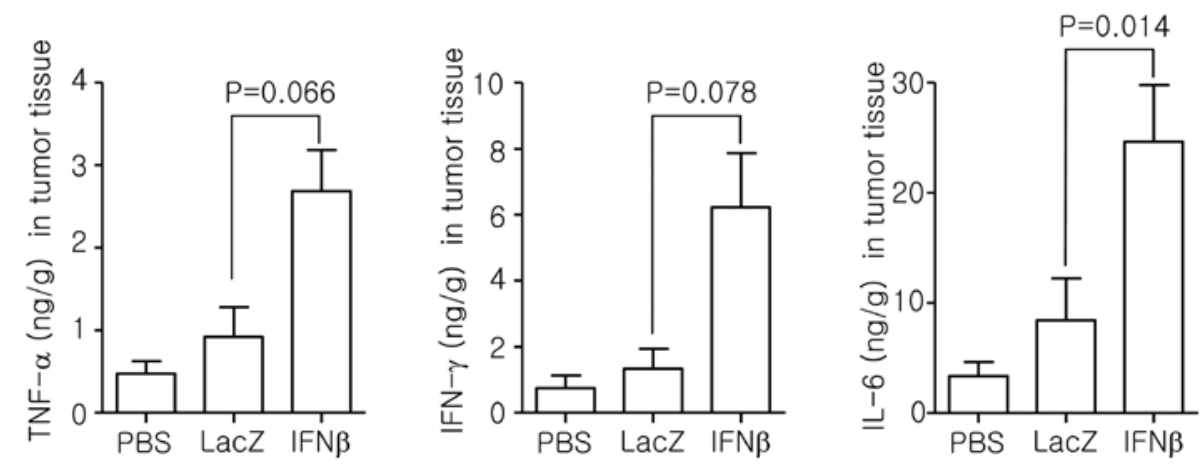

Figure 3. Cytokines induced by Ad-IFN $\beta$ in tumor mass. Ag104L $\mathrm{L}^{\mathrm{d}}$ tumor was established for 2 weeks and Ad-IFN $\beta$ was injected into B6C3F1 mice intratumorally. On Day 3 after the injection, the tumor mass was removed and weighed. The tumor mass was homogenized at $1 \mathrm{~g} / 1 \mathrm{ml}$ PBS containing protease inhibitors. The amount of cytokines in the supernatants was quantified using the cytometric bead array kit.

\section{Results}

IFN- $\beta$-mediated gene therapy reduces established tumors. To test the efficiency of IFN- $\beta$-mediated tumor therapy, Ad-IFN $\beta$ particles were injected into established $\mathrm{Ag} 104 \mathrm{~L}^{\mathrm{d}}$ or $4 \mathrm{~T} 1$ tumor intratumorally 2 times on Days 9 and 12 after tumor inoculation. The treatment reduced $\mathrm{Ag} 104 \mathrm{~L}^{\mathrm{d}}$ tumor size almost completely, and halted 4T1 tumor growth (Fig. 1A and B). Calculation of the number of metastatic cancer cells in the lungs of 4T1-bearing mice showed that the cell number was significantly decreased in the Ad-IFN $\beta$-treated group, compared to the Ad-LacZ-treated group (Fig. 1C).

Therapeutic effect of Ad-IFN $\beta$ is dependent on $C D 8^{+}$T cells. It is known that IFN $\beta$ has direct cytotoxic effects on tumor cells. To explore whether Ad-IFN $\beta$ also induces the cytotoxicity, $\mathrm{Ag} 104 \mathrm{~L}^{\mathrm{d}}$ or $4 \mathrm{~T} 1$ cells were treated with indicated number of Ad-IFN $\beta$ for $24 \mathrm{~h}$ in vitro. Although 4T1 cells were more susceptible to cytotoxicity by Ad-IFN $\beta$ than were $A g 104 L^{d}$ cells, significant cytotoxicity was observed in both of them (Fig. 2A). To determine whether the effect on tumor regression noted in vivo could be attributed more to such direct cytotoxicity of Ad-INF $\beta$, or to a possible immune response induced by Ad-IFN $\beta$, Ad-IFN $\beta$ was injected intratumorally after lympho- cyte depletion and the tumor size was monitored. Although NK cells have a partial function in Ad-IFN $\beta$-mediated tumor therapy, $\mathrm{CD}^{+} \mathrm{T}$, but not $\mathrm{CD} 4^{+} \mathrm{T}$ or $\mathrm{NK}$ cells, were essential in affecting substantial tumor reduction by Ad-IFN $\beta$ (Fig. 2B). Taken together, we conclude that $\mathrm{CD}^{+} \mathrm{T}$ cell activation by Ad-IFN $\beta$ is more important than direct cytotoxicity in tumor regression by Ad-IFN $\beta$.

Ad-IFN $\beta$ is sufficient to modulate the immunological tumor environment. To investigate the modulation of the immunological tumor environment by Ad-IFN $\beta$, we injected Ad-IFN $\beta$ into the established $\mathrm{Ag} 104 \mathrm{~L}^{\mathrm{d}}$ tumor intratumorally on Day 14 and surgically removed the tumor tissues on Day 3 after the Ad-IFN $\beta$ injection. The immunological tumor environment was determined by estimating the level of certain cytokines, i.e., TNF- $\alpha$, IFN- $\gamma$, and IL-6, in the tissue using a CBA assay. Compared to PBS or Ad-lacZ treatment, Ad-IFN $\beta$ treatment induced a steep increase in the amount of these cytokines within the tumor environment; this increase was statistically significant for IL-6 (Fig. 3). Ad-IFN $\beta$ stimulates antigen presenting cells (APC) to produce TNF- $\alpha$ and IL-6, and induces communication between APC and NK cells to drive positive regulation loop producing higher inflammatory cytokines and IFN- $\gamma$. 
A

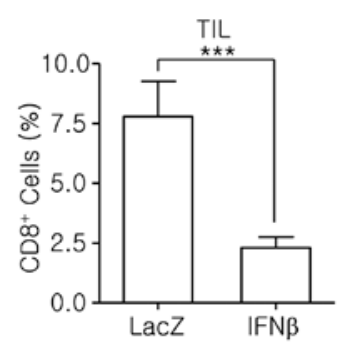

DLN

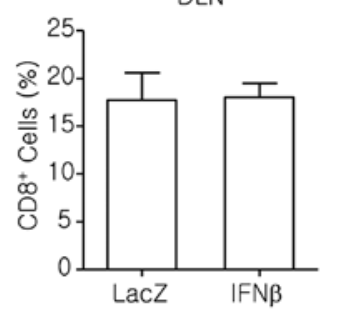

SPL

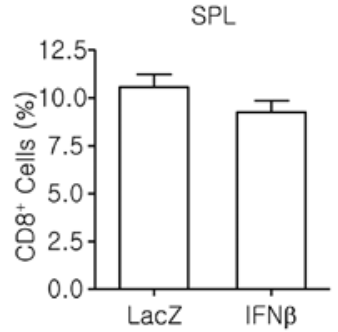

B
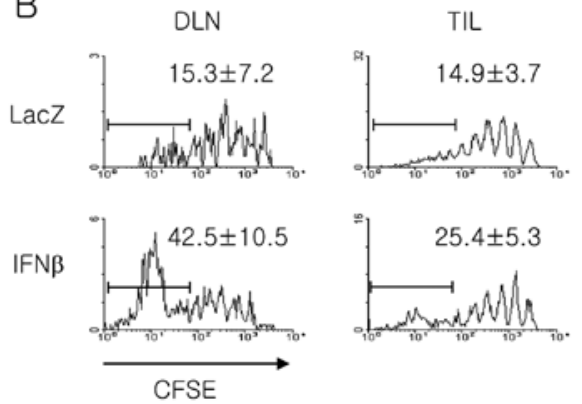

CFSE

Figure 4. Transient decrease of $\mathrm{CD}^{+} \mathrm{T}$ cells and proliferation of $2 \mathrm{C} \mathrm{CD} 8^{+} \mathrm{T}$ cells. Following Ad-IFN $\beta$ treatment, tumor-infiltrated cells were harvested and stained with anti-CD8 $\mathrm{Ab}(\mathrm{A}) .{ }^{* * *} \mathrm{P}<0.02$. This experiment was repeated at least 3 times. To analyze $\mathrm{Ag}^{-}$-specific $\mathrm{CD}^{+} \mathrm{T}$ cells, $\mathrm{CD}^{+} \mathrm{T}$ cells were isolated from $2 \mathrm{C}$ transgenic mice and labeled with CFSE, and then transferred into tumor-bearing mice, as described in Materials and methods. The percentage of $\mathrm{CD} 8^{+} \mathrm{T}$ cells was calculated on gated $\mathrm{CD} 45^{+}$cells. Tumor infiltrated cells were stained with anti-1B2 Ab for 2C transgenic T cell and anti-CD8 Ab (B). The intensity of CFSE on gated $\mathrm{CD} 8^{+} 1 \mathrm{~B} 2^{+}$cells was analyzed as antigen-specific T cell proliferation. Samples (n=3) were analyzed on a FACSCalibur flow cytometer, and data were analyzed with FlowJo software.

Ad-IFN $\beta$ induces transient lymphocyte depletion and leads to Ag-specific T cell proliferation. To further understand the effects of Ad-IFN $\beta$ on tumor regression, we analyzed the intratumoral $\mathrm{CD} 8^{+} \mathrm{T}$ cell population after intratumoral treatment with Ad-lacZ or Ad-IFN $\beta$. The $\mathrm{CD}^{+} \mathrm{T}$ cell population was decreased, rather than increased, within the tumor mass by Day 3, and was recovered by Day 7, after Ad-IFN $\beta$ treatment. The decrease was not observed in the draining lymph nodes or spleen, but only within the tumor mass (Fig. 4A). $\mathrm{CD}^{+} \mathrm{T}$-cell population showed the same tendency with the $\mathrm{CD}^{+} \mathrm{T}$-cell population (data not shown). To investigate the mechanism underlying tumor regression, in spite of transient $\mathrm{CD} 8^{+} \mathrm{T}$-cell depletion, we transferred CFSE-labeled $2 \mathrm{C} \mathrm{CD} 8^{+}$ $\mathrm{T}$ cells, having a specific T-cell receptor (TCR) for the $\mathrm{L}^{\mathrm{d}}$ antigen, into $\mathrm{Ag} 104 \mathrm{~L}^{\mathrm{d}}$ bearing mice. The $2 \mathrm{C} \mathrm{CD8} 8^{+} \mathrm{T}$ cells showed higher proliferation in the draining lymph nodes and in the tumor mass of the Ad-IFN $\beta$ than in the Ad-lacZ treatment group, suggesting activation of antigen specific $\mathrm{T}$ cells through transient T-cell depletion.

\section{Discussion}

Although type I IFN, especially IFN- $\beta$, is a candidate for cancer treatment, the stability of IFN- $\beta$ in vivo has been an obstacle to clinical application. However, it has been proposed that, should a suitable liposomal or viral delivery system be developed, IFN- $\beta$ might be a potent anticancer drug. In this study, we confirmed that adenovirus-mediated IFN- $\beta$ gene therapy was effective in greatly reducing primary solid and metastatic tumors. In addition, we showed for the first time that the mechanism of antitumor action by IFN- $\beta$ involved IFN- $\beta$-induced transient $\mathrm{T}$ cell depletion and concomitant activation of antigen-specific $\mathrm{T}$ cells.

Type I IFN is produced from plasmacytoid dendritic cells following virus infection, and contributes to the immune response against viral infection and the clearing of the virusinfected cells. Uncontrolled type I IFN expression has also been correlated with autoimmune disease $(25,26)$. Furthermore, IFNs are negative regulators that inhibit cancer cell proliferation and induce apoptosis of cancerous cells (27). Indeed, we showed that application of adenovirally-delivered IFN- $\beta$ also induces apoptosis of $\mathrm{Ag} 104 \mathrm{~L}^{\mathrm{d}}$ and $4 \mathrm{~T} 1$ cells in vitro. Despite this direct cytotoxic effect of Ad-IFN $\beta$ on tumor cells, we demonstrated that $\mathrm{CD} 8^{+} \mathrm{T}$ cell activation by $\operatorname{Ad}-\mathrm{IFN} \beta$ was more important than direct cytotoxicity in tumor regression by Ad-IFN $\beta$ in vivo. Although NK cell activation partially contributed to the antitumor immune response, immunological activation of $\mathrm{CD} 8^{+} \mathrm{T}$ cells was a major cause of the therapeutic effect of IFN- $\beta$, as this therapeutic effect was negated by CD8 ${ }^{+}$ T-cell depletion in vivo. Although Ad-IFN $\beta$ affected the host immune response, such as cytokine production and antigenspecific $\mathrm{T}$ cell proliferation in vivo, this effect was too weak to cause tumor regression. This minor immune response is more likely due to reactivity of the innate immune system that is induced by adenovirus through Toll-like receptor-dependent and -independent pathways (28).

In this study, we found that transient $\mathrm{T}$ cell depletion occurred in the tumor mass after intratumoral administration of Ad-IFN $\beta$. This is probably due to IFN-induced apoptosis of $\mathrm{CD} 8^{+}$naïve $\mathrm{T}$ cells, which has been reported to occur during 
the early stages of viral infection. In these previous reports, the loss of $\mathrm{CD}^{+} \mathrm{T}$ cells was preceded by the development of an antiviral T-cell response $(29,30)$, while apoptosis of the $\mathrm{CD}^{+} \mathrm{T}$ cells was dependent on antigen specificity and interferon receptor-mediated signaling since the loss of $\mathrm{CD}^{+}$ T cells disappeared in IFN-R KO. We speculate that Ad-IFN $\beta$ treatment might induce tumor cell death, which would result in the release of tumor-associated antigens, and lead antigen presenting cells (APC) to produce inflammatory cytokines, induce communication between APC and NK cells, and would accelerate presentation of these antigens which induce the activation of Ag-specific T cells. This would result in the expansion of the antigen-specific $\mathrm{T}$ cell population, which would be activated to kill the tumor cells. By contrast, antigen non-specific $\mathrm{T}$ cells would only be lost in the tumor mass during Ad-IFN $\beta$ treatment because IFN- $\beta$ expression would be restricted to the tumor mass.

In summary, in this study, we propose a novel mechanism for the antitumor effects of an adenovirally-delivered IFN $\beta$ involving induction of a relatively high antitumor immune response through loss of antigen-nonspecific $\mathrm{T}$ cells, similar to that which occurs during the early phase of viral infection.

\section{Acknowledgements}

This study was supported by the Bio and Medical Technology Development Program of the National Research Foundation (NRF) funded by the Korean government (MEST) (20100020667) and by the Next-Generation BioGreen21 (SSAC, PJ008107), Rural Development Administration, Republic of Korea.

\section{References}

1. Kantoff PW, Higano CS, Shore ND, et al: Sipuleucel-T immunotherapy for castration-resistant prostate cancer. N Engl J Med 363: 411-422, 2010.

2. Schwartzentruber DJ, Lawson DH, Richards JM, et al: gp100 peptide vaccine and interleukin-2 in patients with advanced melanoma. N Engl J Med 364: 2119-2127, 2011.

3. Coccia EM, Severa M, Giacomini E, et al: Viral infection and Toll-like receptor agonists induce a differential expression of type I and lambda interferons in human plasmacytoid and monocyte-derived dendritic cells. Eur J Immunol 34: 796-805, 2004.

4. Rothenfusser S, Tuma E, Endres S and Hartmann G: Plasmacytoid dendritic cells: the key to CpG. Hum Immunol 63: 1111-1119, 2002.

5. Asselin-Paturel C, Brizard G, Chemin K, et al: Type I interferon dependence of plasmacytoid dendritic cell activation and migration. J Exp Med 201: 1157-1167, 2005.

6. Beignon AS, McKenna K, Skoberne M, et al: Endocytosis of HIV-1 activates plasmacytoid dendritic cells via Toll-like receptor-viral RNA interactions. J Clin Invest 115: 3265-3275, 2005.

7. Guiducci C, Ott G, Chan JH, et al: Properties regulating the nature of the plasmacytoid dendritic cell response to Toll-like receptor 9 activation. J Exp Med 203: 1999-2008, 2006.

8. Gilliet M, Cao W and Liu YJ: Plasmacytoid dendritic cells: sensing nucleic acids in viral infection and autoimmune diseases. Nat Rev Immunol 8: 594-606, 2008.

9. Havenar-Daughton C, Kolumam GA and Murali-Krishna K: Cutting edge: The direct action of type I IFN on CD4 T cells is critical for sustaining clonal expansion in response to a viral but not a bacterial infection. J Immunol 176: 3315-3319, 2006.
10. McBride S, Hoebe K, Georgel P and Janssen E: Cell-associated double-stranded RNA enhances antitumor activity through the production of type I IFN. J Immunol 177: 6122-6128, 2006.

11. Frenz T, Waibler Z, Hofmann J, et al: Concomitant type I IFN receptor-triggering of $\mathrm{T}$ cells and of $\mathrm{DC}$ is required to promote maximal modified vaccinia virus Ankara-induced T-cell expansion. Eur J Immunol 40: 2769-2777, 2010.

12. Gallagher KM, Lauder S, Rees IW, Gallimore AM and Godkin AJ: Type I interferon (IFN alpha) acts directly on human memory $\mathrm{CD}^{+} \mathrm{T}$ cells altering their response to antigen. J Immunol 183: 2915-2920, 2009.

13. Cho HJ, Hayashi T, Datta SK, et al: IFN-alpha beta promote priming of antigen-specific $\mathrm{CD} 8^{+}$and $\mathrm{CD} 4^{+} \mathrm{T}$ lymphocytes by immunostimulatory DNA-based vaccines. J Immunol 168: 4907-4913, 2002.

14. Forlenza M, de Carvalho Dias JD, Vesely T, Pokorova D, Savelkoul HF and Wiegertjes GF: Transcription of signal-3 cytokines, IL-12 and IFN alpha beta, coincides with the timing of CD8 alpha beta up-regulation during viral infection of common carp (Cyprinus carpio L). Mol Immunol 45: 1531-1547, 2008.

15. Agarwal P, Raghavan A, Nandiwada SL, et al: Gene regulation and chromatin remodeling by IL-12 and type I IFN in programming for CD8 $\mathrm{T}$ cell effector function and memory. J Immunol 183: 1695-1704, 2009.

16. Larsson I, Landstrom LE, Larner E, Lundgren E, Miorner H and Strannegard L: Interferon production in glia and glioma cell lines. Infect Immun 22: 786-789, 1978.

17. Nehashi K, Yoshida J, Wakabayashi T, et al: Growth inhibition of human glioma cells by superinduced human interferon-beta. Neurol Med Chir (Tokyo) 35: 719-722, 1995.

18. Salazar AM, Levy HB, Ondra S, et al: Long-term treatment of malignant gliomas with intramuscularly administered polyinosinic-polycytidylic acid stabilized with polylysine and carboxymethylcellulose: an open pilot study. Neurosurgery 38: 1096-1104, 1996

19. Qin XQ, Tao N, Dergay A, et al: Interferon-beta gene therapy inhibits tumor formation and causes regression of established tumors in immune-deficient mice. Proc Natl Acad Sci USA 95: 14411-14416, 1998

20. Lu W, Fidler IJ and Dong Z: Eradication of primary murine fibrosarcomas and induction of systemic immunity by adenovirus-mediated interferon beta gene therapy. Cancer Res 59: 5202-5208, 1999.

21. Natsume A, Tsujimura K, Mizuno M, Takahashi T and Yoshida J: IFN-beta gene therapy induces systemic antitumor immunity against malignant glioma. J Neurooncol 47: 117-124, 2000.

22. Tada H, Maron DJ, Choi EA, et al: Systemic IFN-beta gene therapy results in long-term survival in mice with established colorectal liver metastases. J Clin Invest 108: 83-95, 2001.

23. Odaka M, Sterman DH, Wiewrodt R, et al: Eradication of intraperitoneal and distant tumor by adenovirus-mediated interferon-beta gene therapy is attributable to induction of systemic immunity. Cancer Res 61: 6201-6212, 2001.

24. Burnette BC, Liang H, Lee Y, et al: The efficacy of radiotherapy relies upon induction of type I interferon-dependent innate and adaptive immunity. Cancer Res 71: 2488-2496, 2011.

25. Swiecki M, Gilfillan S, Vermi W, Wang Y and Colonna M: Plasmacytoid dendritic cell ablation impacts early interferon responses and antiviral NK and CD8(+) T cell accrual. Immunity 33: 955-966, 2010.

26. Swiecki M and Colonna M: Unraveling the functions of plasmacytoid dendritic cells during viral infections, autoimmunity, and tolerance. Immunol Rev 234: 142-162, 2010.

27. Belardelli F, Ferrantini M, Proietti E and Kirkwood JM: Interferon-alpha in tumor immunity and immunotherapy. Cytokine Growth Factor Rev 13: 119-134, 2002.

28. Zhu J, Huang X and Yang Y: Innate immune response to adenoviral vectors is mediated by both Toll-like receptor-dependent and -independent pathways. J Virol 81: 3170-3180, 2007.

29. Jiang J, Lau LL and Shen H: Selective depletion of nonspecific $T$ cells during the early stage of immune responses to infection. J Immunol 171: 4352-4358, 2003.

30. Bahl K, Kim SK, Calcagno C, et al: IFN-induced attrition of CD8 $\mathrm{T}$ cells in the presence or absence of cognate antigen during the early stages of viral infections. J Immunol 176: 4284-4295, 2006. 